\title{
PPAR ligands improve impaired metabolic pathways in fetal hearts of diabetic rats
}

\author{
Melisa Kurtz, Evangelina Capobianco, Nora Martinez, Sabrina Lorena Roberti, \\ Edith Arany ${ }^{1}$ and Alicia Jawerbaum
}

Laboratory of Reproduction and Metabolism, CEFyBO-CONICET, School of Medicine, University of Buenos Aires, Paraguay 2155, 17th Floor, 1121 Buenos Aires, Argentina

${ }^{1}$ Department of Pathology, Schullich School of Medicine and Dentistry, Lawson Health Research Institute, St Joseph's Health Care, University of Western Ontario, London, Ontario, Canada

\begin{abstract}
In maternal diabetes, the fetal heart can be structurally and functionally affected. Maternal diets enriched in certain unsaturated fatty acids can activate the nuclear receptors peroxisome proliferator-activated receptors (PPARs) and regulate metabolic and anti-inflammatory pathways during development. Our aim was to investigate whether PPAR $\alpha$ expression, lipid metabolism, lipoperoxidation, and nitric oxide (NO) production are altered in the fetal hearts of diabetic rats, and to analyze the putative effects of in vivo PPAR activation on these parameters. We found decreased PPAR $\alpha$ expression in the hearts of male but not female fetuses of diabetic rats when compared with controls. Fetal treatments with the PPAR $\alpha$ ligand leukotriene $B_{4}$ upregulated the expression of PPAR $\alpha$ and target genes involved in fatty acid oxidation in the fetal hearts. Increased concentrations of triglycerides, cholesterol, and phospholipids were found in the hearts of fetuses of diabetic rats. Maternal treatments with diets supplemented with $6 \%$ olive oil or $6 \%$ safflower oil, enriched in unsaturated fatty acids that can activate PPARs, led to few changes in lipid concentrations, but up-regulated PPAR $\alpha$ expression in fetal hearts. NO production, which was increased in the hearts of male and female fetuses in the diabetic group, and lipoperoxidation, which was increased in the hearts of male fetuses in the diabetic group, was reduced by the maternal treatments supplemented with safflower oil. In conclusion, impaired PPAR $\alpha$ expression, altered lipid metabolism, and increased oxidative and nitridergic pathways were evidenced in hearts of fetuses of diabetic rats and were regulated in a genderdependent manner by treatments enriched with PPAR ligands.
\end{abstract}

\section{Correspondence} should be addressed to A Jawerbaum Email a.jawerbaum@gmail.com
Journal of Molecular

Endocrinology

(2014) 53, 237-246

\section{Introduction}

Maternal diabetes can impair the development of the fetus and lead to adverse consequences evident in the offspring both during the perinatal period and in later life (Michael Weindling 2009, Simeoni \& Barker 2009, Ali \& Dornhorst 2011). The fetal heart is a target organ that can be structurally and functionally affected by maternal

\author{
Key Words \\ - diabetes in pregnancy \\ - fetus \\ - heart \\ - nitric oxide \\ - PPAR
}

diabetes (Molin et al. 2004, Corrigan et al. 2009). In the fetal period, the heart uses glucose and lactate as main oxidative substrate sources and then switches to fatty acids in the neonate, to assure proper energy metabolism according to dietary and physiological conditions (Finck 2007). 
Peroxisome proliferator-activated receptor alpha (PPAR $\alpha$ ), the first of the three PPAR isotypes identified, is an important regulator of myocardial lipid metabolism that also contributes to the control of inflammation and oxidative stress (Wahli \& Michalik 2012, Lee et al. 2013, Palomer et al. 2013). PPAR $\alpha$ is expressed in the fetal heart and its expression increases after birth (Abbott 2009). In mouse models of diabetes, the fetal heart shows decreased PPAR $\alpha$ expression (Lindegaard $\&$ Nielsen 2008). In experimental models, both PPAR $\alpha$ inactivation and overexpression can lead to metabolic alterations in the heart (Finck 2007, Lindegaard \& Nielsen 2008). In adult diabetic patients, chronic inflammation and alterations in energy and lipid homeostasis are involved in cardiac dysfunction (Palomer et al. 2013). In the cardiovascular system, several metabolic and antiinflammatory pathways are regulated by ligands of the nuclear receptor PPAR $\alpha$ both through transactivation and transrepression mechanisms (Lefebvre et al. 2006, Wahli $\&$ Michalik 2012). Fibrates are pharmacological ligands of PPAR $\alpha$ used to regulate dyslipidemia, which ameiorate cardiovascular diseases and reduce pro-inflammatory markers in the heart of diabetic patients (Lefebvre et al. 2006, Lee et al. 2013). The natural ligands of PPAR $\alpha$ include leukotriene (LT) $\mathrm{B}_{4}$, and certain unsaturated fatty acids such as oleic acid and linoleic acid, which can be efficiently transferred through the placenta (Hihi et al. 2002, Herrera et al. 2006, Jawerbaum \& Capobianco 2011).

Diabetes induces a pro-oxidant and pro-inflammatory state in both the non-pregnant and the pregnant states (Calkin \& Thomas 2008, Lappas et al. 2011). In previous studies, in a mild diabetic rat model during pregnancy we have evaluated and found alterations in PPAR $\alpha$ expression and signaling in different fetal organs such as the liver and the lungs (Jawerbaum \& White 2010, Martinez et al. 2011a, Kurtz et al. 2012). In the current study, we used the same diabetic rat model to address whether the fetal heart has altered expression of PPAR $\alpha$ and lipid-oxidizing enzymes, lipid content, nitric oxide (NO) production, and lipid peroxidation. We also carried out fetal treatments with $\mathrm{LTB}_{4}$ and evaluated maternal diets enriched with $6 \%$ olive oil or $6 \%$ safflower oil to identify putative changes in PPAR $\alpha$ expression, lipid metabolism, and oxidative and nitridergic pathways. Considering the known sexual differences in PPAR signaling and in metabolic and heart diseases, the hearts from both female and male fetuses were separately analyzed (Kautzky-Willer \& Handisurya 2009, Yoon 2009, Garcia-Patterson et al. 2011, Mosca et al. 2011).

\section{Materials and methods}

\section{Animals}

Albino Wistar rats bred in our animal facility were fed ad libitum with commercial rat chow (Asociación Cooperativa Argentina, Buenos Aires, Argentina). To induce diabetes, at 2 days of age, neonates were injected with streptozotocin (90 mg/kg, s.c., Sigma-Aldrich) diluted in citrate buffer (0.05 M, pH 4.5, Sigma-Aldrich), as previously described (Jawerbaum \& White 2010, Martinez et al. 2011a). The control animals were injected with citrate buffer alone. The diabetic state was confirmed in 2-monthold rats before mating. The rats were considered diabetic when they presented fasting glycemia values higher than $130 \mathrm{mg} / \mathrm{dl}$. The guidelines for the care and use of animals approved by the local institution were followed (EXP-UBA 0011821), according to the Principles of Laboratory Animal Care (NIH publication number 85-23, revised 1985, http:// grants1.nih.gov/grants/olaw/references/phspol.htm).

Control and diabetic female rats were mated with control males. The first day of pregnancy was confirmed by the presence of sperm cells in vaginal smears. On this day, both control and diabetic animals were randomized into two groups: group 1, animals whose fetuses were injected with the PPAR $\alpha$ ligand $\mathrm{LTB}_{4}$ or vehicle on days 19, 20, and 21 of pregnancy and group 2, animals fed with diets supplemented with $6 \%$ olive oil or $6 \%$ safflower oil, enriched in natural PPAR ligands, from days 1 to 21 of pregnancy.

In group 1 , to inject the fetuses, the animals $(n=9$ control and $n=9$ diabetic rats) were anesthetized in a $\mathrm{CO}_{2}$ chamber on days 19,20, and 21 of pregnancy and a slight anesthesia maintained with ether vapors. An abdominal incision was performed and the left horn of the uterus was exposed. The fetuses were numbered from the ovary and alternatively injected with $\mathrm{LTB}_{4}(0.1 \mathrm{nmol} /$ fetus dissolved in vehicle; Cayman Chemical Co., Ann Arbor, MI, USA) or vehicle ( $0.3 \mu \mathrm{l}$ ethanol/fetus, dissolved in saline solution) subcutaneously on their backs through the uterine wall, as described previously (Kurtz et al. 2012). The entire surgery lasted $<10 \mathrm{~min}$ and the animals were completely recovered after $15 \mathrm{~min}$. On day 21 of pregnancy and after $3 \mathrm{~h}$ of the last injection, the rats were killed and the hearts from female and male fetuses were explanted and preserved as described below.

In group 2, control and diabetic mothers were fed from days 1 to 21 of pregnancy either with a standard diet or with diets enriched in unsaturated fatty acids that activate PPARs: 6\% olive oil (354\% enriched in oleic acid) and 6\% safflower oil (226\% enriched in linoleic acid)

Published by Bioscientifica Ltd. 
( $n=9$ in each experimental group), as described previously (Martinez et al. 2012). The compositions of the diets were as follows: standard diet (g/100 g): carbohydrates (50); proteins (25); fat (5), major fatty acids 16:0 (0.58), 18:0 (0.16), 18:1 (1.27), 18:2 (1.99), 18:3 (0.73); olive oilsupplemented diet $(\mathrm{g} / 100 \mathrm{~g})$ : carbohydrates (48); proteins (24); fat (11), major fatty acids 16:0 (1.55), 18:0 (0.26), 18:1 (5.77), 18:2 (2.41), 18:3 (0.57); and safflower oilsupplemented diet (g/100 g): carbohydrates (47); proteins (23); fat (11), major fatty acids 16:0 (0.97), 18:0 (0.25), 18:1 (1.81), 18:2 (6.49), 18:3 (0.55).

All animals from groups 1 and 2 were killed by decapitation on day 21 of pregnancy. Maternal and fetal blood samples were collected in heparinized tubes and plasma was preserved at $-80^{\circ} \mathrm{C}$. Under a stereomicroscope, fetuses were sexed and the fetal hearts explanted. The hearts from male and female fetuses were randomly selected and either preserved in RNA stabilization solution (RNAlater, Invitrogen) for further evaluation of gene expression of PPAR $\alpha$ and lipid-oxidizing enzymes or preserved at $-80^{\circ} \mathrm{C}$ for further analysis of lipid content, NO production, and lipoperoxidation.

\section{Metabolic assays}

Glycemia values were measured by the Accu-Chek reagent strips and a glucometer Accu-Chek (Bayer Diagnostics) in blood samples obtained from the tail vein of the mothers. The maternal and fetal glycemia and triglyceridemia were measured in plasma by an enzymatic colorimetric commercial kit (Wiener Lab, Rosario, Argentina).

\section{Expression of PPAR $\alpha$ and rate-limiting enzymes in lipid oxidation}

The gene expression of PPAR $\alpha$ and the rate-limiting enzymes in lipid oxidation of acyl CoA oxidase (ACO) and carnitine palmitoyltransferase 1 (CPT1) were evaluated by RT-PCR, a semi-quantitative method, as described previously (Kurtz et al. 2012). Briefly, RNA was extracted from the hearts of one female and one male fetus from each rat ( $n=9$ rats in each experimental group) with TRI reagent (Genbiotech, Buenos Aires, Argentina) in accordance with the manufacturer's instructions. cDNA was synthesized by incubating $1 \mu \mathrm{g}$ of extracted RNA in a first-strand buffer containing MMLV enzyme (Promega), random primer hexamers, and each of all four dNTPs (Invitrogen), in accordance with the MMLV manufacturer's instructions. cDNA ( $2 \mu \mathrm{l}$, selected to work within the linear range) was amplified by PCR in a buffer containing dNTPs, magnesium chloride solution, Taq polymerase (GoTaq Polymerase, Promega), and each specific primer in accordance with the Taq polymerase manufacturer's instructions.

Primers for PPAR $\alpha$ were as follows: forward, 5'-TCACACAATGCAATCCGTTT-3' and reverse: 5'-GGCCTTGACCTTGTTCATGT-3', whose amplification product is a 177-bp fragment (Kurtz et al. 2012). The primers for Aco were as follows: forward: 5'-CCAATCACGCAATAGTTCTGG-3' and reverse, 5'-CGCTGTATCGTATGGCGAT-3', whose amplification product is a 363-bp fragment (Lillycrop et al. 2005). The primers for Cpt1 were as follows: forward, 5'-TATCGTCGCACATTAGACCGT- $3^{\prime}$ and reverse, 5'-CATCTATGACCTCCTGGCACT-3', whose amplification product is a 715-bp fragment (Cheng et al. 2004). The primers for the ribosomal protein L30, used as an internal control, were as follows: forward, 5'-CCATCTTGGCGTCTGATCTT-3' and reverse, 5'-GGCGAGGATAACCAATTTC-3', whose amplification product is a 201-bp fragment (Primer 3 Software, Cambridge, MA, USA). The initial step in the reaction was $95^{\circ} \mathrm{C}$ for $5 \mathrm{~min}$, followed by 33 cycles for PPAR $\alpha, 33$ cycles for ACO, 34 cycles for CPT1, and 26 cycles for L30, as selected to work within the linear range. Each cycle consisted of denaturation at $95^{\circ} \mathrm{C}$ for $15 \mathrm{~s}$, primer annealing at $58{ }^{\circ} \mathrm{C}$ for $30 \mathrm{~s}$, and extension at $72^{\circ} \mathrm{C}$ for $15 \mathrm{~s}$. The resulting products were separated on a $2 \%$ agarose gel and stained with SYBR safe (Invitrogen). The images were taken with an ImageQuant spectrophotometer (GE Healthcare, Buckinghamshire, UK) and the density of the bands was quantified with the Image $\mathrm{J}$ Software (NIH, Bethesda, MD, USA) and normalized to L30.

\section{Analysis of lipid content}

Lipid content was determined by thin layer chromatography, as described previously (Martinez et al. 2011a). Briefly, hearts from three female or three male fetuses from each rat were pooled and homogenized $(n=9$ rats in each experimental group) in $500 \mu \mathrm{l}$ PBS and protein content in the homogenates was measured by the Bradford assay. The tissue lipids were extracted from $470 \mu \mathrm{l}$ of each homogenate by three rounds of organic extraction in methanol:chloroform (2:1). The lipids were developed by thin layer chromatography in $0.2 \mathrm{~mm}$ silica gel plates (Merck), using hexane:ether:acetic acid (80:20:2, v:v:v) as the developing solvent mixture. The lipid species were stained with iodine vapors, identified, and quantified by comparison with known the amounts of standards on the same plate, and densitometric analysis was performed using the Image J Software.

Published by Bioscientifica Ltd. 


\section{Evaluation of NO production}

NO production was evaluated by measuring the concentration of its stable metabolite nitrates/nitrites, as previously determined (Kurtz et al. 2012), by using a commercial assay kit (Cayman Chemical Co.). For this, hearts of two female or two male fetuses from each rat were pooled and homogenized $(n=9$ rats in each experimental group) in $1 \mathrm{ml}$ Tris- $\mathrm{HCl}$ buffer of $\mathrm{pH} \mathrm{7.6,}$ and an aliquot was separated for protein analysis. The nitrates in the supernatant were reduced to nitrites by nitrate reductase, and the total nitrites were measured by the Griess method (Green et al. 1982). The optical densities were measured at $540 \mathrm{~nm}$ in a microtiter plate using nitrates as standard.

\section{Analysis of lipoperoxidation}

Lipoperoxidation was assessed as described previously (Martinez et al. 2011a), by measuring the concentrations of thiobarbituric acid reactive substances (TBARS), a method widely used to assess peroxidation of fatty acids (Ohkawa et al. 1979). Briefly, hearts from two female or two male fetuses from each rat were pooled and homogenized ( $n=9$ rats in each experimental group) in $100 \mathrm{mM}$ Tris- $\mathrm{HCl}$ buffer $(0.1 \mathrm{mM}, \mathrm{pH}$ 7.4). The homogenate was added with $40 \%$ trichloroacetic acid (Merck). After centrifugation, the supernatant was added with an equal volume of thiobarbituric acid ( $46 \mathrm{mM}$; Sigma-Aldrich), the solution was heated at $95^{\circ} \mathrm{C}$ and, after cooling, quantified spectrophotometrically at $540 \mathrm{~nm}$. Different concentrations of malondialdehyde (Sigma-Aldrich) subjected to the same conditions as the tissue homogenates were used as standards.

\section{Statistical analysis}

Data are presented as means \pm s.E.M. Groups were compared by two-way ANOVA in conjunction with Bonferroni's test. A $P$ value $<0.05$ was considered statistically significant.

\section{Results}

Decreased expression of PPAR $\alpha$ and enzymes involved in lipid oxidation in the hearts of fetuses from diabetic rats: effects of fetal treatments with a PPAR $\alpha$ activator

We first analyzed the metabolic parameters of experimental group 1 and found that glycemia and triglyceridemia were increased in both mothers and fetuses from diabetic rats compared with controls on day 21 of pregnancy $(P<0.01)$, with no gender differences and no effects of injecting with the PPAR $\alpha$ activator $\mathrm{LTB}_{4}$ on fetus in the groups evaluated (Table 1).

When we evaluated the expression of PPAR $\alpha$, a regulator of lipid metabolism and anti-inflammatory processes in the heart of adults and in different fetal tissues (Martinez et al. 2011a, Kurtz et al. 2012, Lee et al. 2013), we found a decrease in PPAR $\alpha$ expression in the hearts of male but not of female fetuses in the diabetic group compared with controls $(P<0.01$, Fig. $1 \mathrm{~A})$. We also evidenced the ability of the PPAR $\alpha$ ligand $\mathrm{LTB}_{4}(0.1 \mathrm{nmol}$, injected into the fetuses through the uterine wall on days 19,20 , and 21 of pregnancy) to upregulate PPAR $\alpha$ expression in the hearts of female and male fetuses in the diabetic group and of male fetuses in the control group $(P<0.01$, Fig. 1A). We next evaluated the expression of $A c o$ and $C p t 1$, relevant PPAR $\alpha$-target genes that code for ratelimiting enzymes in lipid oxidation. We found a decrease in Aco expression in the hearts of male fetuses but not of female fetuses in the diabetic group compared with controls $(P<0.05$, Fig. 1B), and a decrease in Cpt1 expression in the hearts of male and female fetuses in the diabetic group compared with controls $(P<0.01$, Fig. 1C). The fetal injections with the PPAR $\alpha$ ligand $\mathrm{LTB}_{4}$ $(0.1 \mathrm{nmol})$ led to an increase in Aco expression in the hearts of female and male fetuses in the diabetic group as well as in the hearts of female fetuses in the control group

Table 1 Maternal and fetal metabolic parameters in control and diabetic rats from experimental group 1 whose fetuses were injected with $\mathrm{LTB}_{4}$ or vehicle on days 19, 20, and 21 of pregnancy. Values represent mean \pm s.E.M., obtained from mothers and female or male fetuses from $n=9$ rats in experimental group 1. Two-way ANOVA in conjunction with Bonferroni's test was performed

\begin{tabular}{|c|c|c|}
\hline & Glycemia (mg/dl) & Triglyceridemia $(\mathrm{g} / \mathrm{l})$ \\
\hline \multicolumn{3}{|l|}{ Maternal data } \\
\hline Control & $92 \pm 8$ & $1.9 \pm 0.3$ \\
\hline Diabetic & $214 \pm 24^{a}$ & $4.0 \pm 0.3^{a}$ \\
\hline \multicolumn{3}{|c|}{$\begin{array}{l}\text { Fetal data (combined } \\
\text { males/females) }\end{array}$} \\
\hline Control vehicle & $47 \pm 5$ & $0.54 \pm 0.06$ \\
\hline Control $\mathrm{LTB}_{4}$ & $49 \pm 10$ & $0.60 \pm 0.05$ \\
\hline Diabetic vehicle & $146 \pm 11^{b}$ & $0.89 \pm 0.07^{c}$ \\
\hline Diabetic $\mathrm{LTB}_{4}$ & $135 \pm 9$ & $0.88 \pm 0.04$ \\
\hline
\end{tabular}

${ }^{\mathrm{a}} P<0.001$ diabetic vs control; ${ }^{\mathrm{b}} P<0.01,{ }^{\mathrm{c}} P<0.001$ diabetic with vehicle vs control with vehicle.

Published by Bioscientifica Ltd. 

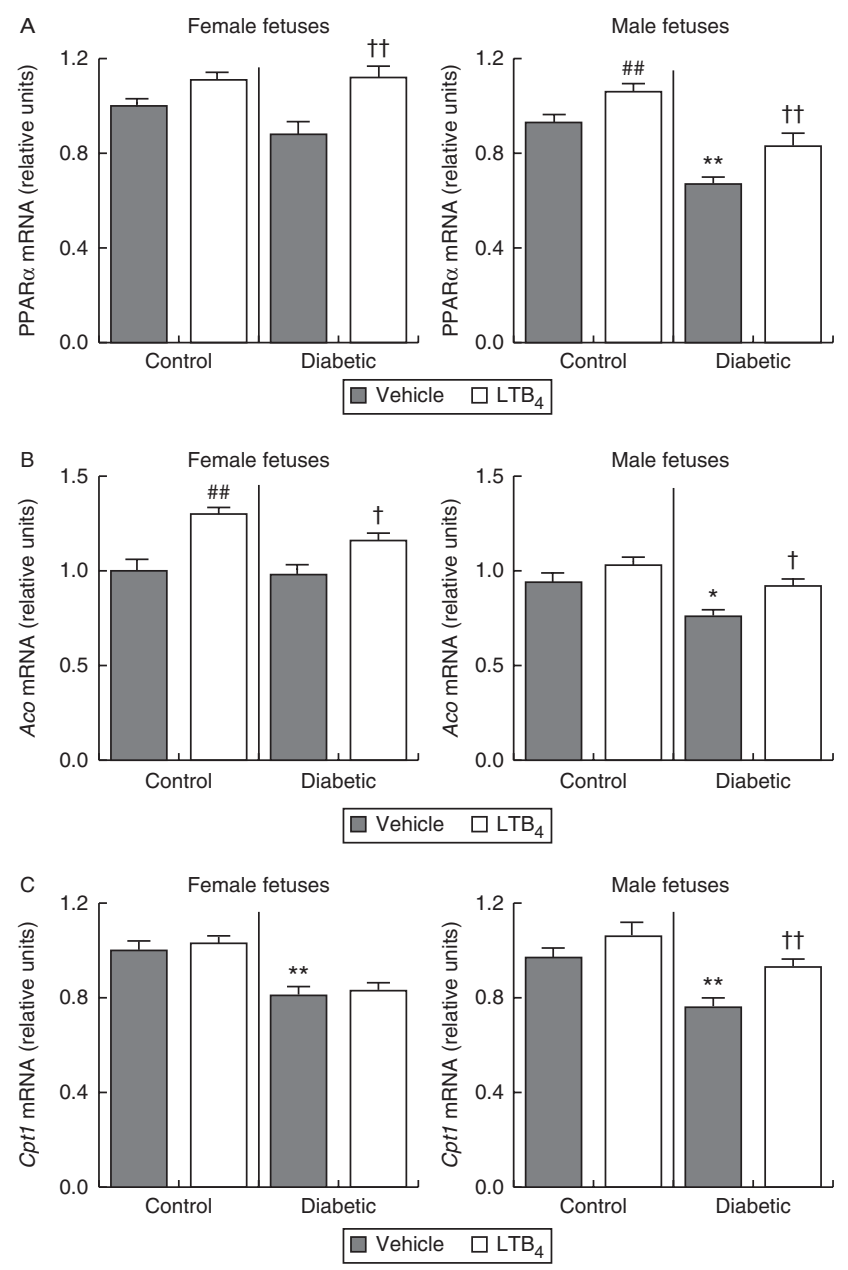

Figure 1

(A) PPAR $\alpha$ expression, (B) Aco expression, and (C) Cpt1 expression in the hearts of fetuses from control and diabetic rats injected with the PPAR $\alpha$ agonist $\mathrm{LTB}_{4}$ or with vehicle on days 19,20 , and 21 of pregnancy. Values represent mean \pm s.E.M., obtained from female or male fetuses from $n=9$ rats in each experimental group. Two-way ANOVA in conjunction with Bonferroni's test was performed. ${ }^{*} P<0.05, * * P<0.01$ diabetic with vehicle vs control with vehicle; ${ }^{\# \#} P<0.01$ control with $\mathrm{LTB}_{4}$ vs control with vehicle; and ${ }^{\dagger} P<0.05,{ }^{\dagger+} P<0.01$ diabetic with $\mathrm{LTB}_{4}$ vs diabetic with vehicle.

$\left(P<0.05\right.$, Fig. 1B). The fetal treatments with $\mathrm{LTB}_{4}$ only led to an increase in Cpt1 expression in the hearts of male fetuses in the diabetic group ( $P<0.01$, Fig. $1 C)$.

\section{Effect of maternal diets enriched with olive oil or safflower oil on lipid concentrations}

Considering the sex-dependent changes observed in the expression of PPAR $\alpha$ and its target genes involved in lipid oxidation in the fetal hearts of diabetic rats, we evaluated lipid concentrations in the hearts of female and male fetuses from control and diabetic rats. We found increased concentrations of triglycerides $(P<0.001)$, cholesterol $(P<0.05)$, and phospholipids $(P<0.05)$ and no changes in cholesteryl esters in the heart of female and male fetuses in the diabetic group compared with controls (Fig. 2). As we have previously shown that dietary supplementation with $6 \%$ olive oil and $6 \%$ safflower oil can regulate lipid content in different fetal tissues and through developmental stages (Capobianco et al. 2008a,b, Kurtz et al. 2014), in this study we analyzed the effect of these dietary supplementations, administered from days 1 to 21 of pregnancy. The metabolic parameters evaluated in these animals (experimental group 2) are shown in Table 2 . On day 21 of pregnancy, increased glycemia and triglyceridemia were observed in both diabetic mother and fetus rats fed the standard diet compared with controls fed the standard diet $(P<0.001)$, with no gender differences, and no effects of the diets supplemented with $6 \%$ olive oil or $6 \%$ safflower oil in the groups evaluated (Table 2 ).

When we analyzed the effect of the maternal diets supplemented with $6 \%$ olive and $6 \%$ safflower oils on lipid content in the fetal heart, we observed only a few changes, all of them evidenced in the hearts of female fetuses: an increase in triglycerides in the diabetic group fed the olive oil-supplemented diet, a decrease in cholesterol in the control group fed the olive oilsupplemented diet, and an increase in cholesteryl esters in the control group fed the safflower oil-supplemented diet $(P<0.05$, Fig. 2$)$.

The absence of marked effects on lipid content was evidenced even when the olive oil- and the safflower oilsupplemented diets induced relevant changes in PPAR $\alpha$ expression in the hearts of both female and male fetuses (Fig. 3A). Indeed, PPAR $\alpha$ expression was negatively regulated by the olive oil-supplemented diet in the hearts of female fetuses in the diabetic group and positively regulated by both the olive oil- and the safflower oilsupplemented diets in the hearts of male fetuses in control and diabetic groups $(P<0.05$, Fig. 3A). No effects were observed when expression of Aco and Cpt1 was evaluated in the control and the diabetic groups fed olive oil- and safflower oil-supplemented diets compared with the respective groups fed the standard diet (Fig. 3B and C).

\section{Effect of maternal diets enriched with olive oil or safflower oil on NO production}

Our previous studies suggest that $\operatorname{PPAR} \alpha$ is a relevant regulator of $\mathrm{NO}$ production in different fetal organs (Martinez et al. 2011b, Kurtz et al. 2012). Excessive

Published by Bioscientifica Ltd. 

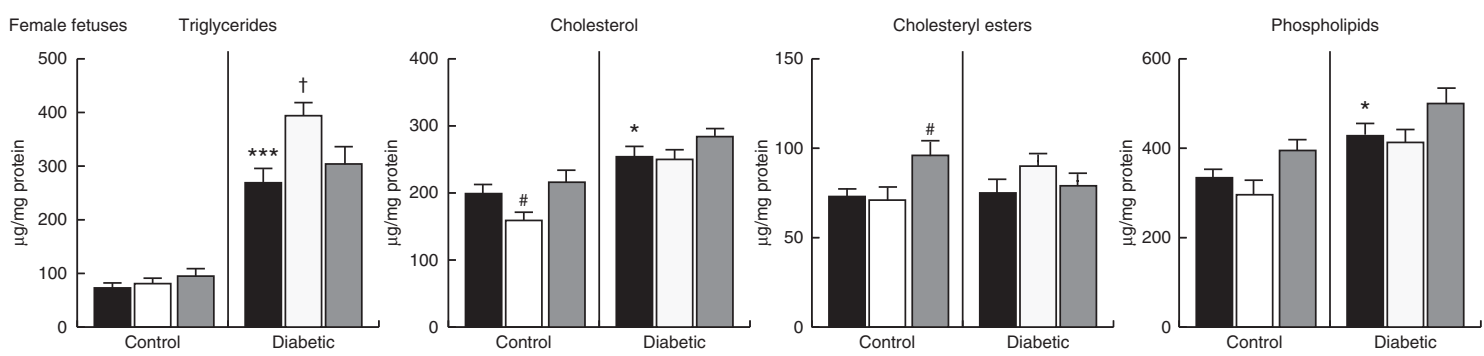

Standard diet $\square$ Olive oil-supplemented diet $\square$ Safflower oil-supplemented diet
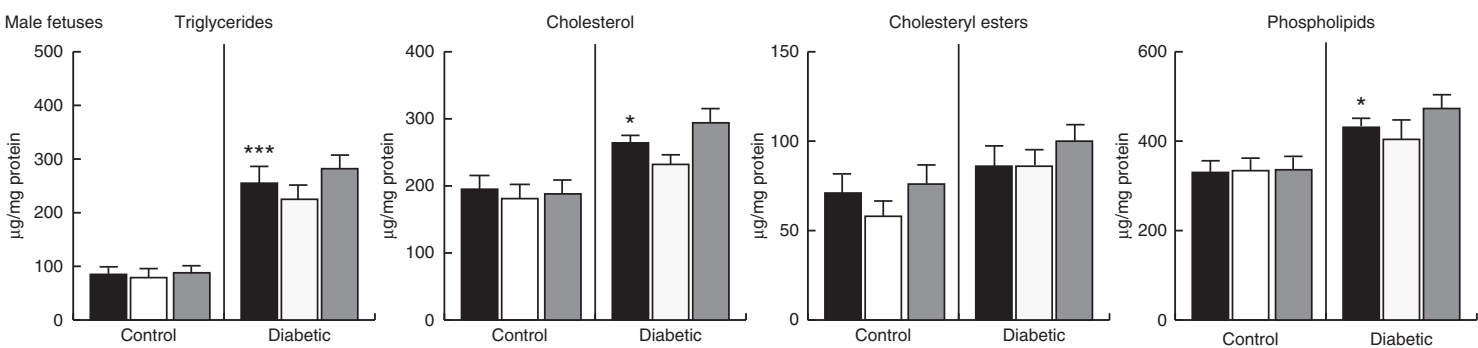

Standard diet $\square$ Olive oil-supplemented diet $\square$ Safflower oil-supplemented diet

\section{Figure 2}

Lipid concentrations in the hearts of fetuses from control and diabetic rats fed with a standard, a $6 \%$ olive oil-supplemented or a $6 \%$ safflower oil-supplemented diet from days 1 to 21 of pregnancy. Values represent mean \pm s.E.M., obtained from female or male fetuses from $n=9$ rats in each experimental group. Two-way ANOVA in conjunction with Bonferroni's test was performed. $* P<0.05, * * * P<0.001$ diabetic with standard diet vs control with standard diet; ${ }^{\#} P<0.05$ control with oil-supplemented diets vs control with standard diet; and ${ }^{\dagger} P<0.05$ diabetic with oil-supplemented diets vs diabetic with standard diet.

production of NO can affect embryo and fetal development and is a marker of a pro-inflammatory state (Lappas et al. 2011). In this work, we found increased nitrates/nitrites concentrations, an index of NO production, in the hearts of female and male fetuses of diabetic rats when compared with controls $(P<0.01$, Fig. 4). We also evidenced the ability of the maternal diets supplemented with olive oil to decrease nitrates/ nitrites (stable NO metabolites) in the hearts of male fetuses in the diabetic group $(P<0.01$, Fig. 4$)$, and the ability of the maternal diets supplemented with $6 \%$ safflower oil to decrease nitrates/nitrites in the hearts of both female and male fetuses in the diabetic group $(P<0.01$, Fig. 4).

Table 2 Maternal and fetal metabolic parameters in control and diabetic rats from experimental group 2 fed with standard diet supplemented with or without $6 \%$ olive oil or $6 \%$ safflower oil from days 1 to 21 of pregnancy. Values represent mean \pm s.E.M., obtained from mothers and female or male fetuses from $n=9$ rats in experimental group 2. Two-way ANOVA in conjunction with Bonferroni's test was performed

\begin{tabular}{|c|c|c|c|c|c|c|}
\hline & \multicolumn{3}{|c|}{ Control } & \multicolumn{3}{|c|}{ Diabetic } \\
\hline & $\begin{array}{l}\text { Standard } \\
\text { diet }\end{array}$ & $\begin{array}{c}\text { Standard diet } \\
\text { supplemented with } \\
6 \% \text { olive oil }\end{array}$ & $\begin{array}{l}\text { Standard diet } \\
\text { supplemented with } \\
6 \% \text { safflower oil }\end{array}$ & $\begin{array}{l}\text { Standard } \\
\text { diet }\end{array}$ & $\begin{array}{c}\text { Standard diet } \\
\text { supplemented with } \\
6 \% \text { olive oil }\end{array}$ & $\begin{array}{l}\text { Standard diet } \\
\text { supplemented with } \\
6 \% \text { safflower oil }\end{array}$ \\
\hline \multicolumn{7}{|l|}{ Maternal data } \\
\hline Glycemia (mg/dl) & $93 \pm 7$ & $105 \pm 9$ & $98 \pm 12$ & $230 \pm 15^{a}$ & $225 \pm 15$ & $230 \pm 14$ \\
\hline Triglyceridemia (g/l) & $2.1 \pm 0.15$ & $2.03 \pm 0.25$ & $2.01 \pm 0.15$ & $4.15 \pm 0.20^{a}$ & $3.87 \pm 0.22$ & $3.92 \pm 0.16$ \\
\hline \multicolumn{7}{|l|}{$\begin{array}{l}\text { Fetal data (combined } \\
\text { males/females) }\end{array}$} \\
\hline Glycemia (mg/dl) & $46 \pm 7$ & $45 \pm 9$ & $44 \pm 6$ & $146 \pm 11^{a}$ & $129 \pm 15$ & $120 \pm 23$ \\
\hline Triglyceridemia (g/l) & $0.52 \pm 0.05$ & $0.59 \pm 0.06$ & $0.48 \pm 0.05$ & $0.98 \pm 0.07^{a}$ & $1.05 \pm 0.10$ & $0.90 \pm 0.08$ \\
\hline
\end{tabular}

${ }^{\text {a }} P<0.01$ diabetic with standard diet vs control with standard diet.

http://jme.endocrinology-journals.org DOI: 10.1530/JME-14-0063 (c) 2014 Society for Endocrinology Printed in Great Britain 

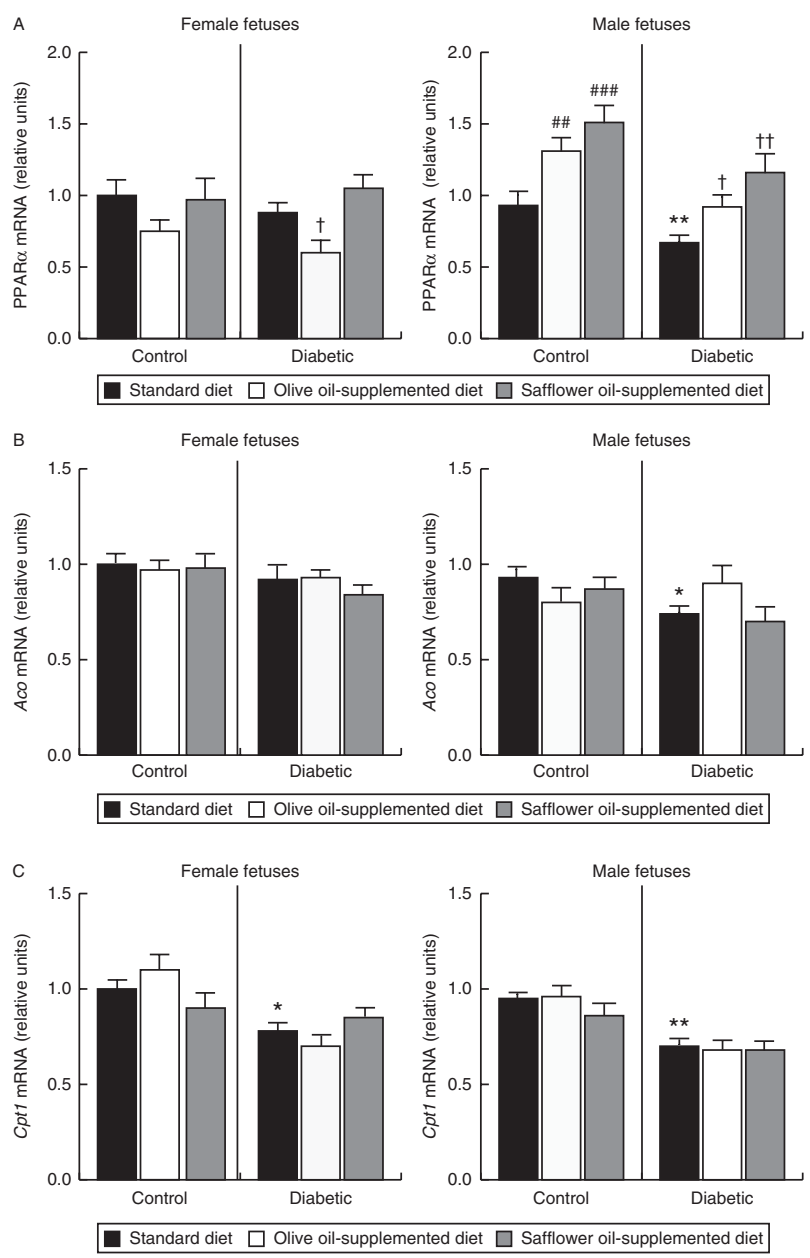

Figure 3

(A) PPAR $\alpha$ expression, (B) Aco expression, and (C) Cpt1 expression in hearts of fetuses from control and diabetic rats fed with a standard, a $6 \%$ olive oil-supplemented or a $6 \%$ safflower oil-supplemented diet from days 1 to 21 of pregnancy. Values represent mean \pm s.E.M., obtained from female or male fetuses from $n=9$ rats in each experimental group. Two-way ANOVA in conjunction with Bonferroni's test was performed. ${ }^{*} P<0.05, * * P<0.01$ diabetic with standard diet vs control with standard diet; ${ }^{\# \#} P<0.01$, \#\#\# $P<0.001$ control with oil-supplemented diets vs control with standard diet; and ${ }^{\dagger} P<0.05,{ }^{\dagger \dagger} P<0.01$ diabetic with oil-supplemented diets vs diabetic with standard diet.

\section{Effect of maternal diets enriched with olive oil or safflower oil on lipoperoxidation}

As PPAR $\alpha$ activation can regulate anti-oxidant pathways in different tissues during development (Martinez et al. $2011 a, b)$ and lipoperoxidation is a marker of oxidative stress previously found to be increased in the fetuses and placentas of diabetic rats (Jawerbaum \& White 2010), we next evaluated lipoperoxidation in the heart of fetuses from control and diabetic rats that were treated with or without diets supplemented with $6 \%$ olive oil or
$6 \%$ safflower oil from days 1 to 21 of pregnancy. Lipoperoxidation was observed to be increased in the hearts of male fetuses $(P<0.01)$, although not in the hearts of female fetuses from diabetic rats when compared with controls (Fig. 5). We also evidenced the ability of the maternal diets supplemented with $6 \%$ safflower oil, although not of those supplemented with $6 \%$ olive oil, to decrease lipoperoxidation in the hearts of male fetuses in the diabetic group $(P<0.01$, Fig. 5).

\section{Discussion}

In this study, we found sex-dependent increases in lipid content, NO production, and lipoperoxidation, together with decreased expression of PPAR $\alpha$ and rate-limiting enzymes involved in lipid oxidation in the hearts of term fetuses of diabetic rats. Fetal or maternal treatments with PPAR activators regulated most of the parameters evaluated in a sex-dependent way. PPAR $\alpha$ expression was upregulated both by fetal treatments with PPAR $\alpha$ ligands and by maternal treatments with diets enriched with PPAR ligands during gestation, thus indicating the ability of these treatments to amplify PPAR $\alpha$ signaling pathways in the fetal heart.

PPAR $\alpha$ is a master regulator of lipid oxidation in metabolic tissues such as liver, kidney, and heart (Lefebvre et al. 2006). In this study, we observed a decrease in PPAR $\alpha$ and its target genes Aco and Cpt1 in the hearts of male fetuses from diabetic rats, although only a decrease in Cpt1 in the hearts of female fetuses in the diabetic group when compared with controls. These decreases, together with

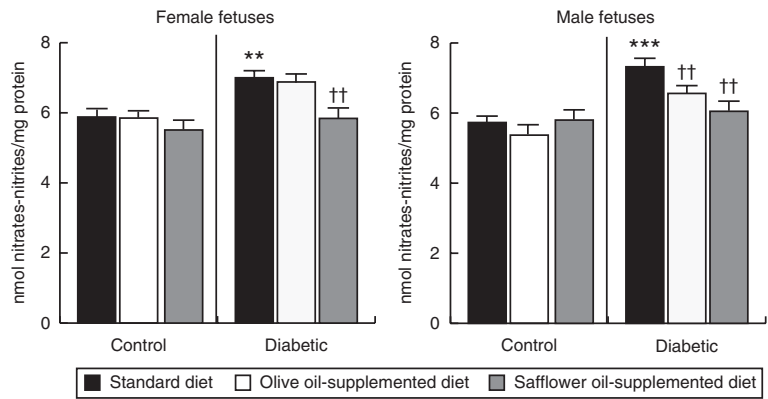

Figure 4

Nitric oxide (NO) production, evaluated through the concentration of NO stable metabolites nitrates/nitrites, in the hearts of fetuses from control and diabetic rats fed with a standard, a $6 \%$ olive oil-supplemented, or a $6 \%$ safflower oil-supplemented diet from days 1 to 21 of pregnancy. Values represent mean \pm s.E.M., obtained from female or male fetuses from $n=9$ rats in each experimental group. Two-way ANOVA in conjunction with Bonferroni's test was performed. $* * P<0.01, * * * P<0.01$ diabetic with standard diet vs control with standard diet and ${ }^{t+} P<0.01$ diabetic with oil-supplemented diets vs diabetic with standard diet. 


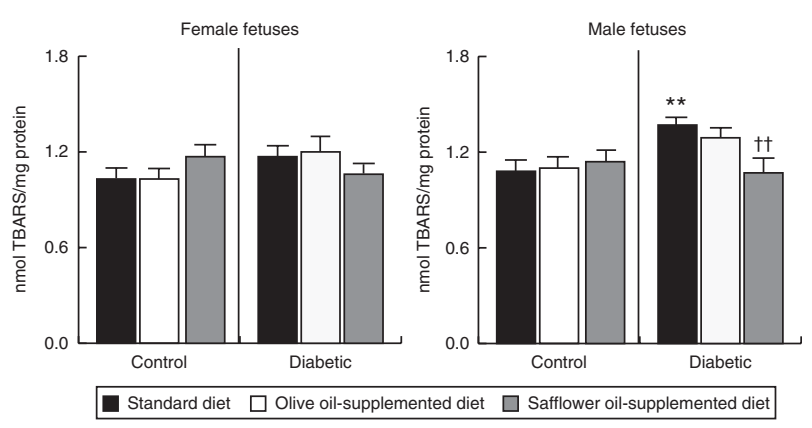

Figure 5

Lipoperoxidation, examined through the concentrations of TBARS, in the hearts of fetuses from control and diabetic rats fed with a standard, a $6 \%$ olive oil-supplemented or a $6 \%$ safflower oil-supplemented diet from days 1 to 21 of pregnancy. Values represent mean \pm s.E.M., obtained from female or male fetuses from $n=9$ rats in each experimental group. Two-way ANOVA in conjunction with Bonferroni's test was performed. $* * P<0.01$ diabetic with standard diet vs control with standard diet and ${ }^{\dagger \dagger} P<0.01$ diabetic with oil-supplemented diets vs diabetic with standard diet.

the increased maternal and fetal triglyceridemia, may be involved in the overaccumulation of lipids in the hearts of fetuses in the diabetes experimental model evaluated. Previous studies performed in Akita mice, a more severe genetic model of diabetes, showed no changes in triglyceride content but a decrease in lipid transporters and in the expression of PPAR $\alpha$ in the fetal hearts (Lindegaard \& Nielsen 2008). It is known that PPAR $\alpha$ regulates lipid oxidation in the hearts of neonates and adults (Finck 2007), but its function as a lipid metabolic sensor is not yet clear in the fetuses. In this work, we found that the PPAR $\alpha$ ligand $\mathrm{LTB}_{4}$ is able to increase the expression of the lipid-oxidizing enzymes ACO and CPT1 in the fetal heart. Nevertheless, maternal diets enriched with PPAR ligands did not increase the expression of ACO and CPT1, and did not lead to a decreased content of lipid species in the fetal heart. It is known that PPAR ligands decrease lipid content in the fetal liver (Martinez et al. 2011a) and that the liver is the main target in treatment with PPAR $\alpha$ ligands in adult animals (Finck 2007). However, in this study, we found that both the maternal diets enriched with PPAR ligands and the fetal treatments with the PPAR $\alpha$ agonist $\mathrm{LTB}_{4}$ led to an increased expression of PPAR $\alpha$ in the fetal heart, indicating that PPAR $\alpha$ signaling is stimulated in this fetal organ by the given treatments. Several studies have shown that different PPAR ligands can induce different conformational changes in PPARs, as well as different biological responses (Hostetler et al. 2005, Gregoire et al. 2009). Indeed, ligand activation stabilizes the interaction between PPAR and RXR, enhances the formation of functional PPAR-RXR heterodimers, and can also regulate the heterodimerization with different partners (Harmon et al. 2011, Balanarasimha et al. 2014). The resulting interaction plays a key role leading to the formation of complexes, which result in gene activation or repression (Harmon et al. 2011). Thus, it is possible that transactivation pathways are those mainly activated by $\mathrm{LTB}_{4}$ in the fetal heart, leading to the expression of regulation of lipid oxidizing enzymes, whereas transrepression pathways are those mainly activated by the maternal dietary treatments with unsaturated fatty acids. However, further studies are needed to address this point, as this work was limited due to the evaluation of PPAR ligands in different in vivo approaches. The formation of PPAR complexes and the resulting activity are tissue-dependent, and PPARs' capacity to activate or repress metabolic and proinflammatory pathways was similarly evidenced using different in vivo and in vitro approaches in the fetal liver and lung (Harmon et al. 2011, Martinez et al. 2011a, Kurtz et al. 2012).

In the heart, relevant extra-metabolic functions related with the control of the pro-inflammatory and pro-oxidant environment can be exerted by PPAR $\alpha$ activation (Palomer et al. 2013). We found that NO production, which is increased in pro-inflammatory states (Lappas et al. 2011), was increased in the hearts of male and female fetuses from diabetic rats. Previous research has demonstrated that diabetic embryopathy is related with NO overproduction, and that different fetal organs such as liver, lung, and placenta have increased NO production when being developed in a diabetic mother (Martinez et al. 2011a,b, Kurtz et al. 2012). Moreover, in the presence of oxidative stress, NO overproduction leads to the formation of peroxynitrites, which induce severe damage to different organs, including the heart (Mungrue et al. 2002, Lappas et al. 2011). Thus, it was interesting to find that maternal diets enriched with $6 \%$ olive oil (only in male fetuses) and 6\% safflower oil (in both male and female fetuses) prevented the overproduction of $\mathrm{NO}$ in the hearts of fetuses from diabetic rats. Future research is needed to identify whether putative epigenetic changes are involved in the fetal changes observed, and to analyze the effects of these treatments in the heart of neonates.

It is known that cardiac dysfunction is sex-dependent, possibly in part due to the differential ability of estrogens to regulate lipid metabolism (Kautzky-Willer \& Handisurya 2009, Oosthuyse \& Bosch 2012). PPAR $\alpha$ signaling is also sex-dependent due to the effects of estrogens and androgens on PPAR $\alpha$ expression and due to the use of common coactivators by different nuclear

Published by Bioscientifica Ltd. 
receptors (Collett et al. 2000, Yoon 2009, Benz et al. 2012). Indeed, we have previously found sex-dependent effects of $\operatorname{PPAR} \alpha$ agonists in different tissues even at fetal stage (Kurtz et al. 2014). Interestingly, in this study, we found that only the heart of male fetuses showed increased lipoperoxidation in the diabetic group. Increased oxidative stress, related with impairments in energy metabolism, stress in endoplasmic reticulum, and apoptosis, has been described in the heart of adult diabetic animals (Li et al. 2007, Palomer et al. 2013).

Previous research has identified the ability of maternal diets enriched with PPAR ligands to reduce oxidative stress during embryo development and to reduce proinflammatory markers in the placenta and fetal lungs (Higa et al. 2012, Kurtz et al. 2012, Martinez et al. 2012). A limitation of this study was that, due to the lack of sufficient biological material, we were unable to measure NO production and lipid peroxidation in the $\mathrm{LTB}_{4}$-treated group. Although the $6 \%$ olive oil-supplemented diet is enriched with both oleic acid and polyphenols that can exert antioxidant properties (Martin-Pelaez et al. 2013), only the maternal treatments supplemented with $6 \%$ safflower oil were able to decrease lipoperoxidation in the hearts of male fetuses from diabetic rats. This may be due to the increased ability of the safflower oil-supplemented diet to amplify PPAR $\alpha$ signaling pathways. Indeed, we showed that this diet leads to a greater increase in PPAR $\alpha$ expression in the hearts of fetuses from diabetic rats. In addition, safflower oil is enriched with linoleic acid, which can activate PPARs by itself and by the production of eicosanoids that can further activate PPARs (Jawerbaum $\&$ Capobianco 2011).

In conclusion, the fetal hearts evaluated in the mild diabetic rat model were profoundly affected, as evidenced by overaccumulation of lipid, increased NO, and lipoperoxidation, which may lead to heart dysfunction later in life. These alterations were more marked in the hearts of male fetuses, which showed reduced expression of PPAR $\alpha$ and target genes involved in fatty acid oxidation. Moreover, PPAR $\alpha$ signaling in the fetal heart was mainly activated by the maternal dietary treatment enriched with $6 \%$ safflower oil, leading to the regulation of lipoperoxidation and NO production, by ameliorating the pro-oxidant and pro-inflammatory environment and thus may prevent the future development of cardiac dysfunction.

\section{Declaration of interest}

The authors declare that there is no conflict of interest that could be perceived as prejudicing the impartiality of the research reported.

\section{Funding}

This work was supported by Grants from Agencia de Promoción Científica y Tecnológica of Argentina and GlaxoSmithKline (PICTO-GSK 2012-0054), from Agencia de Promoción Científica y Tecnológica of Argentina (PICT 2010-0034), and from the Lawson Health Research Institute Internal Research Fund (IRF 01-11).

\section{Acknowledgements}

The authors thank Vet. Marcela Márquez and Tech. Enzo Cuba for the valuable help with animal handling.

\section{References}

Abbott BD 2009 Review of the expression of peroxisome proliferatoractivated receptors alpha (PPAR $\alpha)$, beta (PPAR $\beta)$, and gamma $(\operatorname{PPAR} \gamma)$ in rodent and human development. Reproductive Toxicology $\mathbf{2 7}$ 246-257. (doi:10.1016/j.reprotox.2008.10.001)

Ali S \& Dornhorst A 2011 Diabetes in pregnancy: health risks and management. Postgraduate Medical Journal 87 417-427. (doi:10.1136/ pgmj.2010.109157)

Balanarasimha M, Davis AM, Soman FL, Rider SD Jr \& Hostetler HA 2014 Ligand-regulated heterodimerization of peroxisome proliferatoractivated receptor alpha with liver X receptor alpha. Biochemistry $\mathbf{5 3}$ 2632-2643. (doi:10.1021/bi401679y)

Benz V, Kintscher U \& Foryst-Ludwig A 2012 Sex-specific differences in type 2 diabetes mellitus and dyslipidemia therapy: PPAR agonists. Handbook of Experimental Pharmacology 387-410.

Calkin AC \& Thomas MC 2008 PPAR agonists and cardiovascular disease in diabetes. PPAR Research 2008 245410. (doi:10.1155/2008/245410)

Capobianco E, Martinez N, Higa R, White V \& Jawerbaum A $2008 a$ The effects of maternal dietary treatments with natural PPAR ligands on lipid metabolism in fetuses from control and diabetic rats. Prostaglandins, Leukotriens, and Essential Fatty Acids 79 191-199. (doi:10.1016/j.plefa.2008.08.003)

Capobianco E, White V, Higa R, Martinez N \& Jawerbaum A $2008 b$ Effects of natural ligands of PPAR $\gamma$ on lipid metabolism in placental tissues from healthy and diabetic rats. Molecular Human Reproduction 14 491-499. (doi:10.1093/molehr/gan039)

Collett GP, Betts AM, Johnson MI, Pulimood AB, Cook S, Neal DE \& Robson CN 2000 Peroxisome proliferator-activated receptor alpha is an androgen-responsive gene in human prostate and is highly expressed in prostatic adenocarcinoma. Clinical Cancer Research 6 3241-3248.

Corrigan N, Brazil DP \& McAuliffe F 2009 Fetal cardiac effects of maternal hyperglycemia during pregnancy. Birth Defects Research. Part A, Clinical and Molecular Teratology 85 523-530. (doi:10.1002/bdra.20567)

Cheng L, Ding G, Qin Q, Xiao Y, Woods D, Chen YE \& Yang Q 2004 Peroxisome proliferator-activated receptor delta activates fatty acid oxidation in cultured neonatal and adult cardiomyocytes. Biochemical and Biophysical Research Communications 313 277-286. (doi:10.1016/ j.bbrc.2003REF16=10.1159/000091507)

Finck BN 2007 The PPAR regulatory system in cardiac physiology and disease. Cardiovascular Research 73 269-277. (doi:10.1016/j.cardiores. 2006.08.023)

Garcia-Patterson A, Aulinas A, Sojo L, Ginovart G, Adelantado JM, de Leiva A \& Corcoy R 2011 Poorer perinatal outcome in male newborns of women with pregestational diabetes mellitus. Diabetic Medicine $\mathbf{2 8}$ 436-439. (doi:10.1111/j.1464-5491.2011.03227.x)

Green LC, Wagner DA, Glogowski J, Skipper PL, Wishnok JS \& Tannenbaum SR 1982 Analysis of nitrate, nitrite, and [15N]nitrate in biological fluids. Analytical Biochemistry 126 131-138. (doi:10.1016/ 0003-2697(82)90118-X)

Published by Bioscientifica Ltc. 
Gregoire FM, Zhang F, Clarke HJ, Gustafson TA, Sears DD, Favelyukis S, Lenhard J, Rentzeperis D, Clemens LE, Mu Y et al. 2009 MBX-102/JNJ39659100, a novel peroxisome proliferator-activated receptor-ligand with weak transactivation activity retains antidiabetic properties in the absence of weight gain and edema. Molecular Endocrinology 23 975-988. (doi:10.1210/me.2008-0473)

Harmon GS, Lam MT \& Glass CK 2011 PPARs and lipid ligands in inflammation and metabolism. Chemical Reviews 111 6321-6340.

Herrera E, Amusquivar E, Lopez-Soldado I \& Ortega H 2006 Maternal lipid metabolism and placental lipid transfer. Hormone Research 65 (Suppl 3) 59-64. (doi:10.1159/000091507)

Higa R, Kurtz M, Mazzucco MB, Musikant D, White V \& Jawerbaum A 2012 Folic acid and safflower oil supplementation interacts and protects embryos from maternal diabetes-induced damage. Molecular Human Reproduction 18 253-264. (doi:10.1093/molehr/gar080)

Hihi AK, Michalik L \& Wahli W 2002 PPARs: transcriptional effectors of fatty acids and their derivatives. Cellular and Molecular Life Sciences 59 790-798. (doi:10.1007/s00018-002-8467-x)

Hostetler HA, Petrescu AD, Kier AB \& Schroeder F 2005 Peroxisome proliferator-activated receptor alpha interacts with high affinity and is conformationally responsive to endogenous ligands. Journal of Biological Chemistry 280 18667-18682. (doi:10.1074/jbc.M412062200)

Jawerbaum A \& White V 2010 Animal models in diabetes and pregnancy. Endocrine Reviews 31 680-701. (doi:10.1210/er.2009-0038)

Jawerbaum A \& Capobianco E 2011 Review: Effects of PPAR activation in the placenta and the fetus: implications in maternal diabetes. Placenta 32 (Suppl 2) S212-S217. (doi:10.1016/j.placenta.2010.12.002)

Kautzky-Willer A \& Handisurya A 2009 Metabolic diseases and associated complications: sex and gender matter!. European Journal of Clinical Investigation 39 631-648. (doi:10.1111/j.1365-2362.2009.02161.x)

Kurtz M, Martinez N, Capobianco E, Higa R, Fornes D, White V \& Jawerbaum A 2012 Increased nitric oxide production and genderdependent changes in PPAR $\alpha$ expression and signaling in the fetal lung from diabetic rats. Molecular and Cellular Endocrinology 362 120-127. (doi:10.1016/j.mce.2012.05.018)

Kurtz M, Capobianco E, Careaga VP, Martinez N, Mazzucco MB, Maier M \& Jawerbaum A 2014 PPAR ligands regulate lipid content, metabolism and composition in fetal lungs of diabetic rats. Journal of Endocrinology 220 345-359. (doi:10.1530/JOE-13-0362)

Lappas M, Hiden U, Desoye G, Froehlich J, Mouzon SH \& Jawerbaum A 2011 The role of oxidative stress in the pathophysiology of gestational diabetes mellitus. Antioxidants \& Redox Signaling 15 3061-3100. (doi:10.1089/ars.2010.3765)

Lee TI, Kao YH, Chen YC, Huang JH, Hsiao FC \& Chen YJ 2013 Peroxisome proliferator-activated receptors modulate cardiac dysfunction in diabetic cardiomyopathy. Diabetes Research and Clinical Practice 100 330-339. (doi:10.1016/j.diabres.2013.01.008)

Lefebvre P, Chinetti G, Fruchart JC \& Staels B 2006 Sorting out the roles of PPAR $\alpha$ in energy metabolism and vascular homeostasis. Journal of Clinical Investigation 116 571-580. (doi:10.1172/JCI27989)

Li Z, Zhang T, Dai H, Liu G, Wang H, Sun Y, Zhang Y \& Ge Z 2007 Involvement of endoplasmic reticulum stress in myocardial apoptosis of streptozocin-induced diabetic rats. Journal of Clinical Biochemistry and Nutrition 41 58-67. (doi:10.3164/jcbn.2007008)

Lillycrop KA, Phillips ES, Jackson AA, Hanson MA \& Burdge GC 2005 Dietary protein restriction of pregnant rats induces and folic acid supplementation prevents epigenetic modification of hepatic gene expression in the offspring. Journal of Nutrition 135 1382-1386.
Lindegaard ML \& Nielsen LB 2008 Maternal diabetes causes coordinated down-regulation of genes involved with lipid metabolism in the murine fetal heart. Metabolism 57 766-773. (doi:10.1016/j.metabol. 2008.01.016)

Martin-Pelaez S, Covas MI, Fito M, Kusar A \& Pravst I 2013 Health effects of olive oil polyphenols: recent advances and possibilities for the use of health claims. Molecular Nutrition \& Food Research 57 760-771. (doi:10.1002/mnfr.201200421)

Martinez N, White V, Kurtz M, Higa R, Capobianco E \& Jawerbaum A 2011 a Activation of the nuclear receptor PPAR $\alpha$ regulates lipid metabolism in foetal liver from diabetic rats: implications in diabetes-induced foetal overgrowth. Diabetes/Metabolism Research and Reviews 27 35-46. (doi:10.1002/dmrr.1151)

Martinez N, Kurtz M, Capobianco E, Higa R, White V \& Jawerbaum A $2011 b$ $\operatorname{PPAR} \alpha$ agonists regulate lipid metabolism and nitric oxide production and prevent placental overgrowth in term placentas from diabetic rats. Journal of Molecular Endocrinology 47 1-12. (doi:10.1530/ JME-10-0173)

Martinez N, Sosa M, Higa R, Fornes D, Capobianco E \& Jawerbaum A 2012 Dietary treatments enriched in olive and safflower oils regulate seric and placental matrix metalloproteinases in maternal diabetes. Placenta 33 8-16. (doi:10.1016/j.placenta.2011.10.015)

Michael Weindling A 2009 Offspring of diabetic pregnancy: short-term outcomes. Seminars in Fetal \& Neonatal Medicine 14 111-118. (doi:10.1016/j.siny.2008.11.007)

Molin DG, Roest PA, Nordstrand H, Wisse LJ, Poelmann RE, Eriksson UJ \& Gittenberger-De Groot AC 2004 Disturbed morphogenesis of cardiac outflow tract and increased rate of aortic arch anomalies in the offspring of diabetic rats. Birth Defects Research. Part A, Clinical and Molecular Teratology 70 927-938. (doi:10.1002/bdra.20101)

Mosca L, Barrett-Connor E \& Wenger NK 2011 Sex/gender differences in cardiovascular disease prevention: what a difference a decade makes. Circulation 124 2145-2154. (doi:10.1161/CIRCULATIONAHA.110. 968792)

Mungrue IN, Gros R, You X, Pirani A, Azad A, Csont T, Schulz R, Butany J, Stewart DJ \& Husain M 2002 Cardiomyocyte overexpression of iNOS in mice results in peroxynitrite generation, heart block, and sudden death. Journal of Clinical Investigation 109 735-743. (doi:10.1172/ JCI0213265)

Ohkawa H, Ohishi N \& Yagi K 1979 Assay for lipid peroxides in animal tissues by thiobarbituric acid reaction. Analytical Biochemistry 95 351-358. (doi:10.1016/0003-2697(79)90738-3)

Oosthuyse T \& Bosch AN 2012 Oestrogen's regulation of fat metabolism during exercise and gender specific effects. Current Opinion in Pharmacology 12 363-371. (doi:10.1016/j.coph.2012.02.008)

Palomer X, Salvado L, Barroso E \& Vazquez-Carrera M 2013 An overview of the crosstalk between inflammatory processes and metabolic dysregulation during diabetic cardiomyopathy. International Journal of Cardiology 168 3160-3172. (doi:10.1016/j.ijcard.2013.07.150)

Simeoni U \& Barker DJ 2009 Offspring of diabetic pregnancy: long-term outcomes. Seminars in Fetal \& Neonatal Medicine 14 119-124. (doi:10.1016/j.siny.2009.01.002)

Wahli W \& Michalik L 2012 PPARs at the crossroads of lipid signaling and inflammation. Trends in Endocrinology and Metabolism 23 351-363. (doi:10.1016/j.tem.2012.05.001)

Yoon M 2009 The role of PPAR $\alpha$ in lipid metabolism and obesity: focusing on the effects of estrogen on PPAR $\alpha$ actions. Pharmacological Research 60 151-159. (doi:10.1016/j.phrs.2009.02.004)

Received in final form 9 August 2014

Accepted 13 August 2014

Accepted Preprint published online 13 August 2014 http://jme.endocrinology-journals.org DOI: 10.1530/JME-14-0063
() 2014 Society for Endocrinology Printed in Great Britain 